\title{
Experimental study of heat-killed oocysts of Cryptosporidium Parvum in Balb/ c Mice
}

\author{
Mohammed S. Khudhair ${ }^{1 *}$; Nabeel E.S. Al-Niaeemi ${ }^{2}$ \\ ${ }^{1}$ The Directorate General of Education Nineveh, Mosul, Iraq \\ ${ }^{2}$ Department of Biology, College of Education for Pure Science, University of Mosul, Mosul, Iraq \\ Email: ${ }^{1 *}$ ddm432@yahoo.com, ${ }^{2}$ nabeel.e.s@gmail.com
}

(Received May 02, 2019; Accepted December 24, 2019; Available online June 01, 2020)

DOI: 10.33899/edusj.2020.165305, (C) 2020, College of Education for Pure Science, University of Mosul.

This is an open access article under the CC BY 4.0 license (http://creativecommons.org/licenses/by/4.0/).

\begin{abstract}
The present study investigated the possibility of infecting Mus musculus mice, experimentally, with cryptosporidiosis by inoculation with Cryptosporidium parvum oocysts, after treatment with temperatures $\left(70^{\circ} \mathrm{C}\right)$ and non-treated oocysts, single or double doses, aiming at enrichment of information related to existence of oocysts infected, outside the body of the host when subjected to temperatures. Criteria taken into consideration are the period spent by the parasite inside the body of the host, number of oocytes shed by the parasite with the host's stool, total and differential leukocyte count. The Results of the present study shows:

1- Shedding of Oocysts started at the $4^{\text {th }}$ day post infection by non-treated Oocysts, at single dose, and continued until the day 35 post infection, whereas with the challenge dose it continued until the $17^{\text {th }}$ day post infection.

2- Temperature at $\left(70 \mathrm{C}^{\circ}\right)$ killed the Oocysts as infection of mice didn't occur.

3- Generally, a gradual increase in total and differential leukocyte count on infection with nontreated Oocysts at day 3 post infection.
\end{abstract}

Keywords: Cryptosporidium parvum, leukocyte, infected oocysts.




أشارت هذه الدراسة إلى إحداث الإصابة بداء البويغيات الخبيئة Cryptosporidiosis تجريبياً في الفئران البيض نوع وذلك من خلال تجريعها بأكياس بيض الطفيل Cryptosporidium parvum musculus بعد قتلها بتعريضها إلى درجة حرارة (70C $)$ ومجموعة أخرى غير معاملة، وأجريت التجربة بإعطاء جرعة واحدة أو جرعتين من أكياس بيض طفيل البويغيات الخبيئة Cryptosporidium parvum بهدف إغناء المعلومات حول إمكانية بقاء أكياس بيض الطفيلي خمجة خارج جسم المضيف بعد تعرضها إلى درجة حرارة (70C $)$ وتم من خلال هذه الدراسة الأخذ بنظر الاعتبار فترة بقاء الطفيلي في جسم المضيف، وكذلك تم حساب عدد أكياس البيض المطروحة في براز المضيف والتعداد الكلي والتفريقي لكريات الدم. بينت الدراسة الحالية النتائج التالية :

1- بدأ طرح أكياس البيض في اليوم الرابع بعد احداث الإصابة باكياس بيض غير معاملة، جرعة واحدة، مستمرة لغاية اليوم الخامس والثثلاثين من احداث الإصابة، في حين استمرت العملية لغاية اليوم السابع عشر بعد احداث الإصابة الثانية. 2- درجة الحرارة (70C 3- لوحظ، بصورة عامة، حدوث ارتفاع تدريجي في التعداد الكلي والتفريقي لكريات الدم البيض عند احداث إصابة، باكياس

$$
\text { بيض غير معاملة منذ اليوم الثالث بعد احداث الإصابة. }
$$

الكلمات المفتاحية : داء البويغيات الخبيئة، كريات الام البيض، أكياس بيض الطفيلي خمجة.

المقدمة

داء البويغيات الخبيئة Cryptosporidiosis هو من الامراض المشــتركـة بين الإنســــان والحيوان Zoonotic diseases المنتشـــرة في العالم [1] والمســـبب المرضـــي لهذا الداء هو طفيل أولي داخل خلوي-خارج ســــايتوبلازمي Intracellular-extracytoplasmic يضم 4800 نوع يقع ضمن شعبة المعقدات القية Phylum: Apicomplexa. [2,3]. وبسبب متانة أكياس بيض هذا الطفيل فهو يعد من مسببات الامراض التي يمكن ان تنتقل مع الماء والغذاء إلى الإنسان والحيوان معا [2]. ركزت الدراسـات، منذ اكتثـاف دور الطفيل في إحداث المرض في الإنسـان والحيوان على تثـخيص الأنواع المختلفة التي تتبع جنس البويغيات الخبيئة ودراسة تأثيرها المرضي وتثخيص الطفيل بالطرق المختلفة وعلاج المرض، ولاتزال الدراسات مسـمرة في المجالات المذكورة آنفا، إلا انه ومنذ منتصـف التسـعينات تقريباً بدأت الدراسـات تتجه نحو تأثيرات البيئة في بقاء ومقاومة أكياس البيض خمجة بعد تعرضــــها لظروف البيئة المختلفة من رطوبة وجفاف التربة ودرجات الحرارة، التي يمكن ان تتعرض لها هذه التربة بمدى واســ يتراوح بين درجات حرارة أقل من الصــفر وأعلى من درجة حرارة 50 ○م. وحيث ان التغيير في درجات حرارة البيئة في مناطق مختلفة من العراق يكون بمدى واســع، حيث أخذت هذه النقطة بنظر الاعتبار ، وأصــبـــ دراسة تأثير درجة الحرارة العالية (70C) على خمجية أكياس البيض لهذا الطفيل من الضرورات لتحديد وبائيته. 
من هنا جاء هدف الدراسة الحالية وهو تعريض أكياس بيض الطفيل لدرجة حرارة 70C لمعرفة مدى إمكانية احتفاظ أكياس البيض بخمجيتها بعد تعريضـها لهذه الدرجة الحرارية، وقد اختيرت الفئران السـويسـرية البيضــاء نوع Mus musculus نموذجاً لإحداث الإصابة التجربية فيها. المواد وطرائق العمل جمع العينات تم جمع 103 عينة غائط من أطفال بعمر يتراوح بين 45 يوماً و 8 سنوات ومن كلا الجنسين (66 ذكور، 37 إناث) من الأطفال الذين يعانون من التهاب المعدة والامعاء المسبب للإسـهال ومن الراقدين في مستثفى السـلام العام ومستثفى ابن الاثير في الموصـل، حيث تم إعطاء ذوي الأطفال قناني بلاســتيكية نظيفة ومرقمة لجميع العينات مدون عليها عمر كل طفل وجنسـه، وحفظت العينات في 2.5\% من محلول ثنائي كرومات البوتاسيوم Potassium dichromate (المحضر بإذابة 25 غم من ثائي كرومات البوتاســيوم في لتر ماء مقطر ) حيث اضـــيف إلى كل حجم من عينة الغائط حجمان من محلول ثنائي كرومات البوتاسيوم[4]، وتم حفظ العينات في الثلاجة بدرجة حرارة C[5] C] فحص عينات الغائط فحصـت عينات الغائط للكثـف عن وجود أكياس بيض طفيل C. parvum باسـتخدام طريقة المسـحات المصـبوغة بصبغة الزيل نلسن المحورة الباردة Modified Zeihl Neelsen stain أو ما يسمى بالصبغة الصامدة للحامض Acid fast [6tain staمع تغيير وقت الصــبغة من 30 دقيقة إلى 5 دقائق بناء على ملاحظات الثــرائح المصــبوغة، بعد ذلك تم حفظ العينات الحاوية على أكياس بيض الطفيل بمحلول دايكرومات البوتاسـيوم ووضـعت في الثلاجة لحين اسـتخدامها في الدراسـة التجريبية [7]. طرح أكياس البيض: تم تثخيص أكياس البيض إعتماداً على Deluol. الاراسة التجريبية الحيوانات المختبرية اسـتخدمت 105 من الفئران المختبرية السـويسـرية البيض Swiss Albino Mice نوع Mus musculus ، ســلالة Balb/c 5 و فئران كمجموعة سيطرة، تم الحصول عليها من بيت الفئران الموجود في وحدة البحوث / كلية التربية / قسم علوم الحياة في جامعة الموصـــلـ وتم تربية الفئران في أقفاص بلاســـيكية نظيفة ومعقدة وتكثيرها تحت ظروف ملائمة من حيث الحرارة وتوفير الغذاء المكون من عليقة من الحبوب وفول الصـــويا وبروتين، وبمعدل 5 فئران / قفص تحت ظروف مســـيطر عليها قبل إجراء التجارب وبواقع فأرة واحدة / قفص بعد إجراء التجارب. وفحصت عينات من براز الفئران يومياً لمدة أسبوع قبل استخدامها في التجارب للتأكد من خلوها من الإصابة باي طفيل ومن ضمنها C. parvum تحضير الجرعات من غائط الأطفال وإصابة الفئران حضـرت الجرعات الخمجة من أكياس بيض طفيل C. parvum المعزولة من براز الاطفال المصـابين بداء البويغيات الخبيئة بالاعتماد على طريقة Freir-Santos et al [9] الأتية: 
- رشحت العينات الموجبة الحاوية على أكياس بيض الطفيل خلال 4 طبقات من الثاش وأخذ الراشح. - - غسـلت عينات البراز المرشـة والمحفوظة في محلول ثنائي كرومات البوتاسـيوم عدة مرات بالماء المقطر وباستعمال جهاز

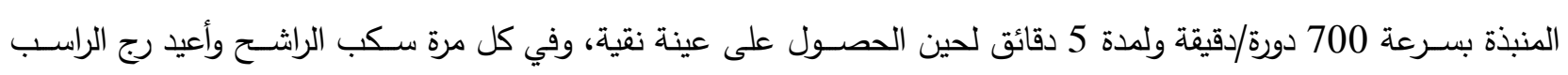
بالماء المقطر . - طوفت العينة باسـتخدام المحلول السكري المشـبع ذي الكثافة النوعية 1.27 (المحضـر من 500 غم سـكر، 320 مل ماء مقطر، 6.5 مل فينول) بسرعة 500 دورة/دقيقة لددة 20 دقيقة [10] . - جمع 20\% من الجزء الطافي الحاوي على عدد كبير من أكياس البيض في أنابيب اختبار ذوات نهاية مخروطية مدببة.

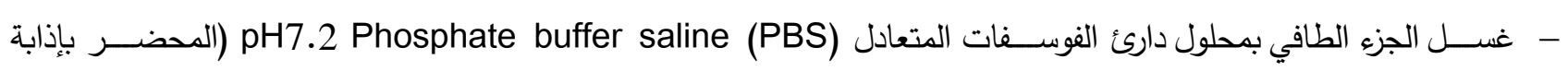

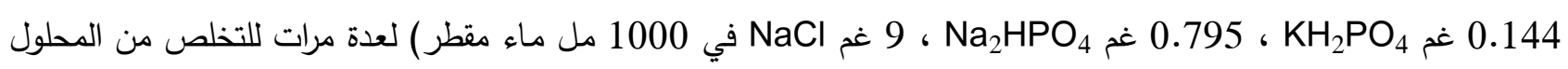
السكري. - اجريت خطوات العزل عند درجة 4C للحفاظ على أكياس البيض من التحطم. وبعد كل عملية فصــلـل أخذت قطرة من الراسب على الثريحة الزجاجية ووضـع عليها غطاء الثريحة وفحصت تحت المجهر بقوة 100X للتأكد من وجود أكياس بيض الطفيل.

حساب الجرعة الخمجة لأكياس البيض تم في هذه المرحلة معرفة أعداد أكياس البيض الموجودة في 1 مل من العينة بعد ان اجريت عليها خطوات العزل، إذ إذ الذهان استخدم لهذا الغرض مقياس عد خلايا الدم (Hemocytometer ) [7] وتم حساب أعداد هذه الأكياس من المعادلة الاتية: [9] $\mathrm{N}=\mathrm{S} / 2 \times 1000$ (oocysts / $\mathrm{ml}$ of sample). $\mathrm{N}=$ number of oocysts in $1 \mathrm{ml}$ of sample. $\mathrm{S}=$ number of oocysts in 2 cubic area. جرعت الفئران المســخدمة في الدراســة بعمر 3-4 اسـابيع، بأوزان متقاربة من الجنسـين، عن طريق الفم باســخدام الأنبوب المعدي Stomach tube بجرعة تحتوي على 3 × 10 كيس بيضـة لكل فأرة [11,12] ـ فحص البراز للفئران المصابة يومياً للتأكد من حدوث الإصابة وذلك عند ظهور الأكياس في البراز باستخدام طريقة الفحص المباشر للبراز [13,14 . المجموعة الأولى: اســـخدم في هذه المجموعة 35 فأراً اعطيت أكياس بيض غير معاملة (غير معاملة) عن طريق الفم بجرعة 3×104


5 فئران) حسب فترات سـب الدم (3 أيام، 15 يوماً و 30 يوماً) بعد إحداث الإصـابة، وتم فحص براز الفئران المصـابة يومياً اعتباراً من اليوم الأول بعد إحداث الإصابة لمتابعة ظهور أكياس البيض في البراز وتسجيل عددها [13,14]. 
المجموعة الثانية ضــت هذه المجموعة 35 فأراً ايضـاً أحدثت فيها الإصـابة بجرعتين بين جرعة واخرى 30 يوماً، احتوت الجرعة الأولى على أكياس بيض غير معاملة والثانية على أكياس بيض مقتولة بالحرارة. المجموعة الثالثة

ضمت هذه المجموعة 35 فأراً ايضـاً عوملت كما في المجموعة الثانية عدا أن الجرعة الأولى كانت أكياس بيض مقتولة بالحرارة، في حين كانت الجرعة الثانية أكياس بيض غير معاملة. المعايير المستخدمة في الاراسة معدل عدد أكياس البيض المطروحة فحص براز الفئران التي أحدثت فيها الإصـابة يومياً اعتباراً من اليوم الأول بعد إحداث الإصـابة الأولى أو الثانية لتقدير عدد الأكياس المطروحة في عشرة حقول مجهرية اختيرت عشوائياً لحين اختفاء ظهور الأكياس في البراز وحسب المعدل لثلاثة مكررات. صورة الام بعد تخدير الفئران بالايثر Diethyl ether تم ســــب الدم من زاويـة العين باتجاه الظفيرة الوريدية خلف مقلة العين بوسـاطة أنبوب شعري حسب طريقة Waynforth [15]. جمع الدم في أنابيب سعة 1 مل حاوية على مانع التخثر (EDTA) لغرض حساب التعداد الكلي والتفاضلي لكريات الدم البيض Total and Differential Leukocyte Count كما يأتي: Total Leukocyte Count التعداد الكلي لكربات الام البيض لـرصن تم حساب الكريات البيض حسب الطريقة المذكورة [16] وأخذ المعدل لثلاثة مكررات. Differential Leukocyte Count التعداد التفاضلي لكريات الام البيض تم تحضير مسحات رقيقة من الدم لغرض حساب العد التنفاضلي لكريات الدم البيض وصبغت بصبغة لثمان ، إذ تم عد 100 خلية بيضاء بأنواعها (الحمضات، و وحيدات النواة، واللمفيات والعدلات) في كل شريحة وحساب النسبة المئوية لكل نوع [17].

\section{Statistical Analysis} التحليل الاحصائي حلت النتائج إحصـائياً باستخدام التصميم العشوائي الكامل CRD) Complete Randomized Design) باستخدام اختبار دنكن المتعدد المدى Duncan's Multiple Range Test ، واختبار t-test) t لإيجاد مســتوى الفروقات بين

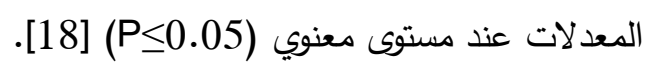




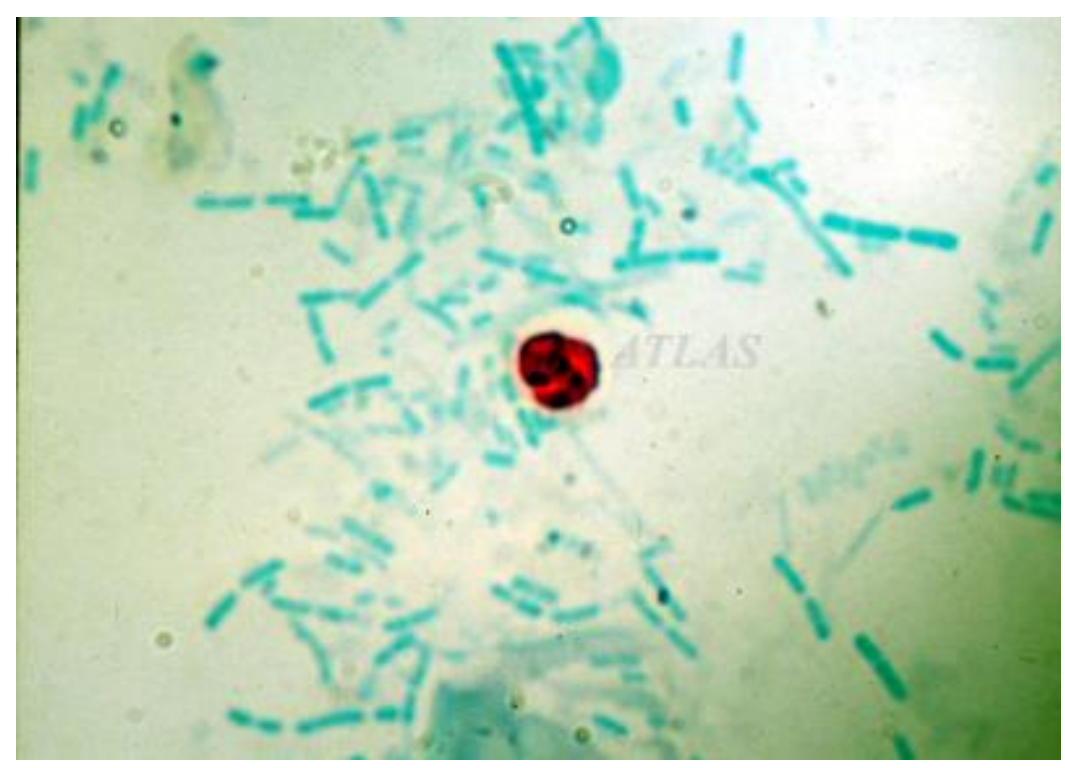

صورة (1) توضح كيس بيض البويغيات الخبيئة في براز الفئران البيض (1000X)

أوضـحت الدراســة أن معدلات أعداد أكياس البيض المطروحة مع براز الفئران المصــابة، تجريبياً، بأكياس بيض الطفيل غير المعاملة والمقتولة بالحرارة لجرعة واحدة وجرعتين. يتضــــح من هذه النتائج أن الفئران المجرعة بجرعة واحدة بدأت بطرح

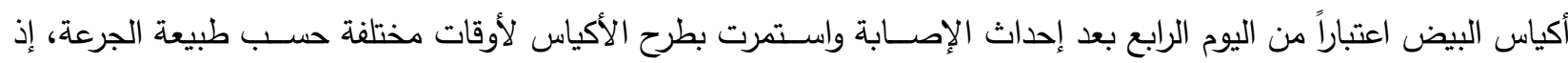
اسـتمر الطرح لغاية اليوم الخامس والثلاثين بعد إحداث الإصـابة بأكياس البيض غير المعاملة، ووصـل العدد ذروته في اليوم العاشر بعد إحداث الإصابة. ولم تلحظ أكياس البيض في براز الفئران المصابة بأكياس بيض مقتولة بالحرارة (شكل 1). وبالنســبة للفئران المجرعة بأكياس بيض غير معاملة في الجرعة الأولى ومقتولة بالحرارة في الجرعة الثانية بدأت بطرح أكياس البيض بأوقات مختلفة بعد إحداث الإصابة واستمرت بطرح الأكياس ايضا لأوقات مختلفة حسب طبيعة الجرعة، فالفئران المجرعة بأكياس بيض غير معاملة بجرعتين بدأت بطرح أكياس البيض اعتباراً من اليوم الرابع بعد إحداث الإصـــابة الثانية، واستمر طرح الأكياس لغاية اليوم السابع عشر بعد إحداث الإصـابة، ووصل العدد ذروته عند اليوم العاشر بعد إحداث الإصـابة الثانية. أما الفئران المجرعة بأكياس بيض غير معاملة في الجرعة الأولى ومقتولة بالحرارة في الجرعة الثانية، فقد بدأت بطرح أكياس البيض اعتباراً من اليوم الأول بعد إحداث الإصـابة الثانية، واستمر طرح الأكياس لغاية اليوم التاسح، ووصل معدل طرح الأكياس ذروته عند اليوم الخامس بعد إحداث الإصابة الثانية، كما في الثكل(2). أمسا فيما يخص الفئران المجرعة بأكياس بيض مقتولة بالحرارة في الجرعة الأولى وغير معاملة في الجرعة الثانية فقد

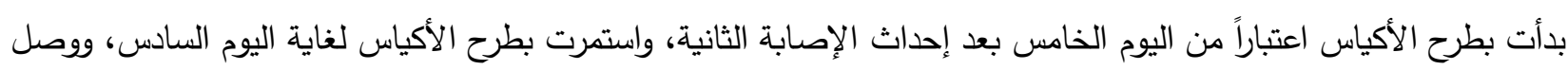
معدل طرح الأكياس ذروته عند اليوم الخامس بعد إحداث الإصابة الثانية كما في الثكل (3). 


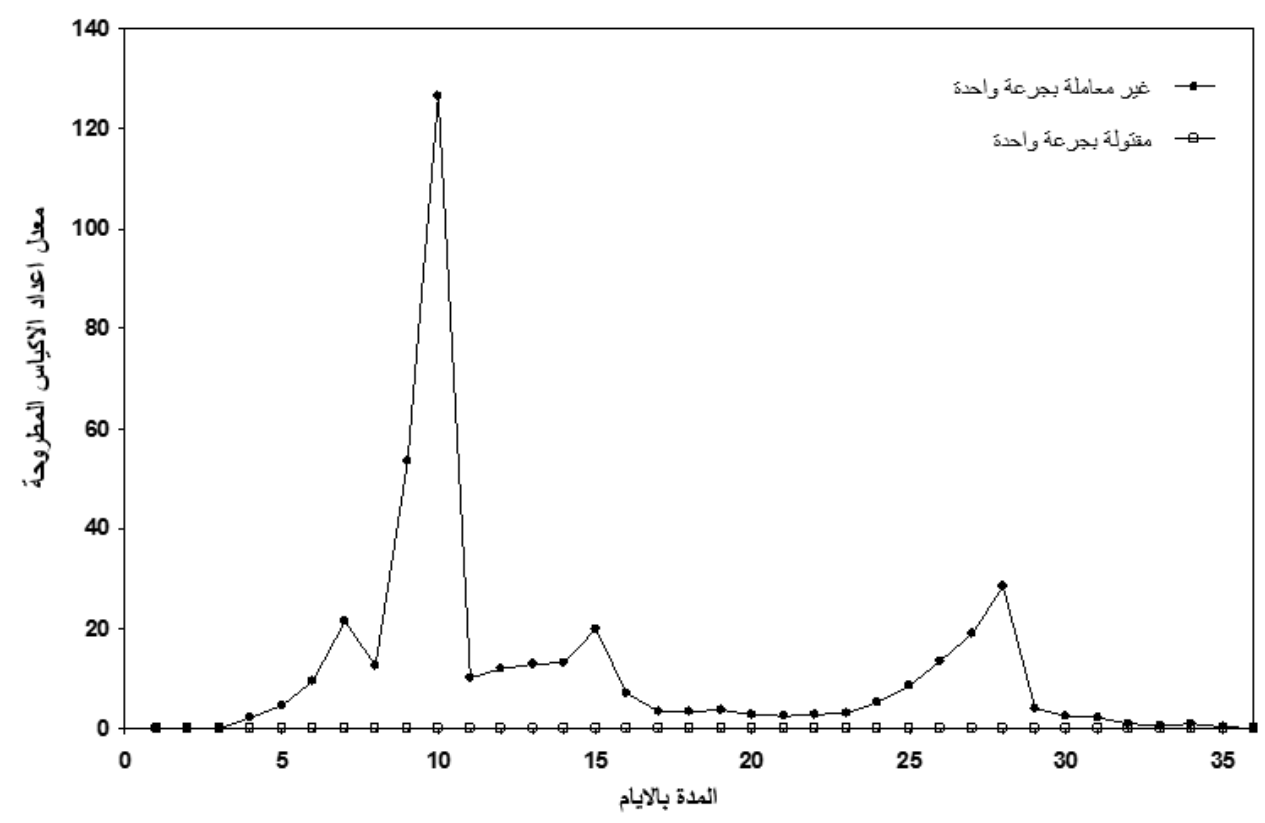

الثكل (1) : معدل اعداد أكياس البيض المطروحة مع البراز للفئران المجرعة بأكياس بيض غير معاملة ومقتولة بالحرارة ولجرعة واحدة مع الزمن

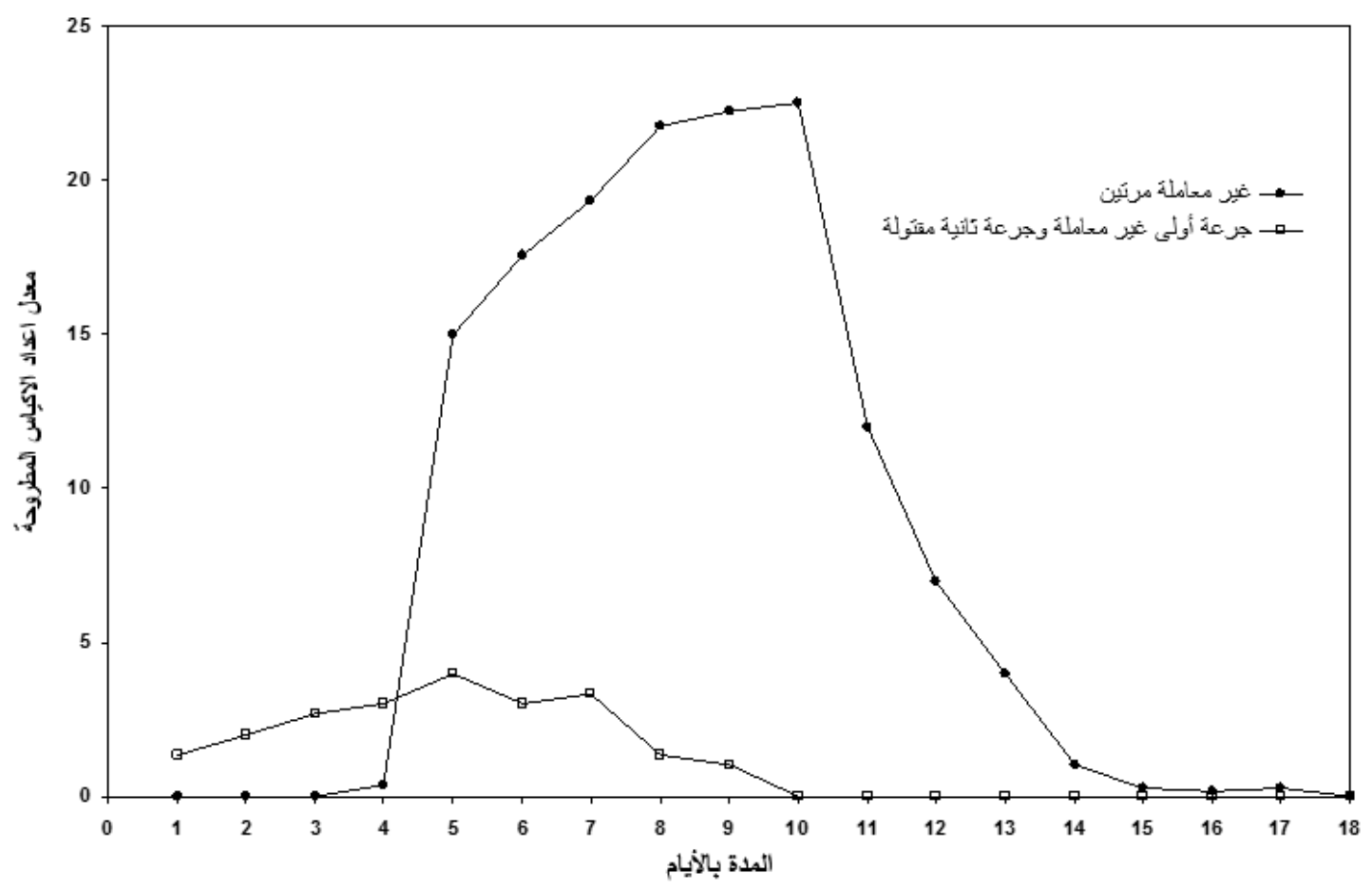

الثكل (2): معدل اعداد أكياس البيض المطروحة مع البراز للفئران المجرعة بأكياس بيض غير معاملة في الجرعة الأولى ومقتولة في الجرعة الثانية مع الزمن 


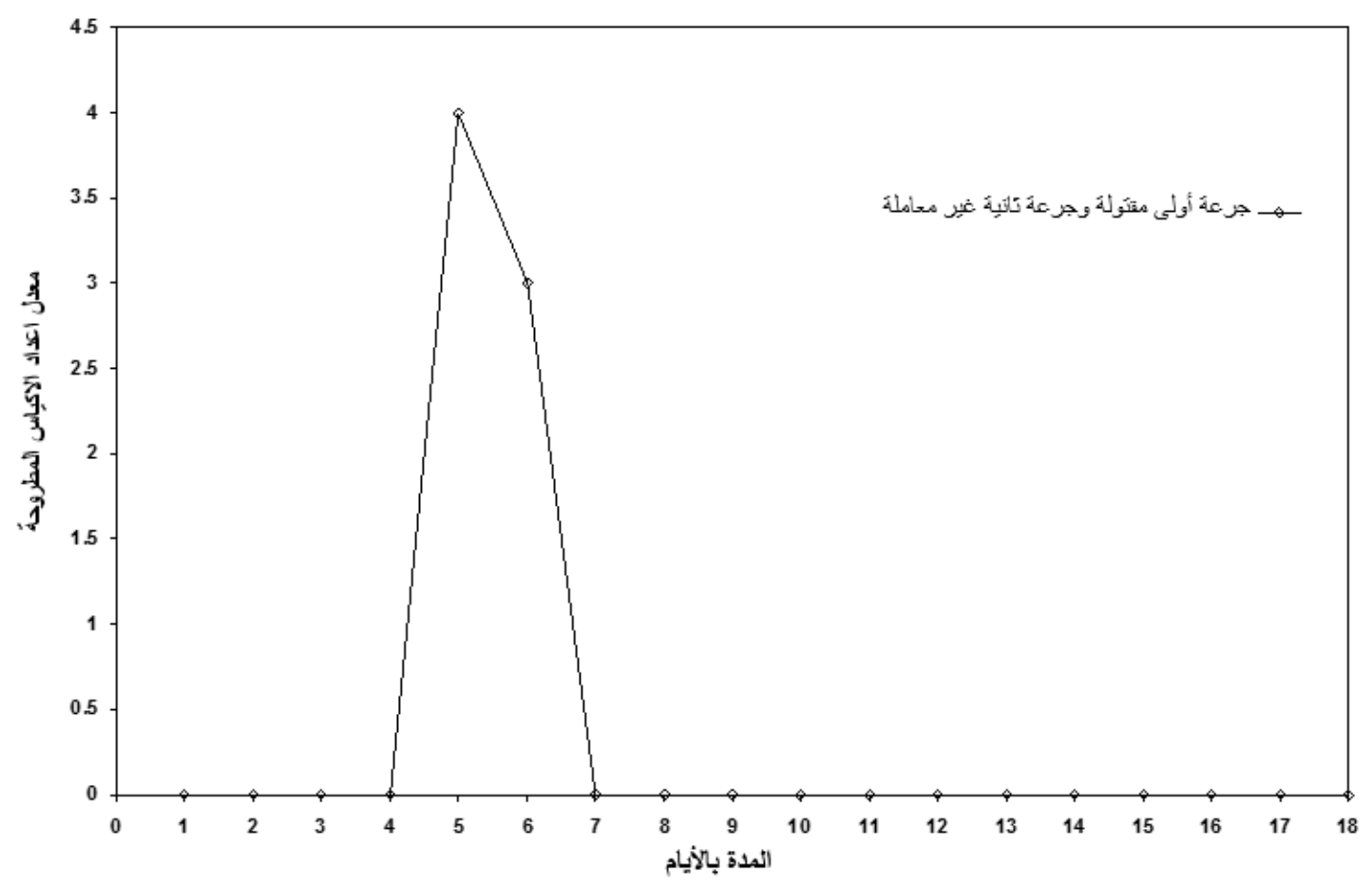

الشكل (3): معدل اعداد أكياس البيض المطروحة مع البراز للفئران المجرعة بأكياس بيض مقتولة في الجرعة الأولى وغير معاملة في الجرعة الثانية مع الزمن

بينت الدراســـة التغيرات الحاصــلة في معدلات الأعداد الكلية لكريات الدم البيض في الفئران المصــابة، تجريبياً، بطفيل البويغيات الخبيئة من خلال تجريعها أكياس بيض غير معاملة واخرى مقتولة بالحرارة، جرعة واحدة أو جرعتين. عند تجريع الفئران بأكياس بيض غير معاملة، جرعة واحدة فقط، لوحظ حدوث ارتفاع تدريجي في معدلات أعداد الكريات


ثلاثين يوماً، إذ استمر العدد بالارتفاع. أما عند إحداث إصـابة بأكياس بيض مقتولة فقد ظهر العكس حيث انخفضــت معدلات أعداد الكريات البيض عند اليوم الثالث من إحداث الإصـابة إلا أنها بدأت بالارتفاع لتصـبح مقاربة جداً لنظيراتها في مجموعة السـيطرة السـالبة بعد ثلاثين يوماً من إحداث الإصــابة (الجدول 1). وعند تجريع الفئران بجرعتين من أكياس البيض، لوحظ، بصـــورة عامة، أنه عند اســـخدام أكياس بيض غير معاملة في الجرعة الأولى غير معاملة أو مقتولة في الجرعة الثانية كان الارتفاع في معدل أعداد الكريات البيض أعلى من نظائره في الحالة الأولى، وبدأ العدد بالانخفاض بعد ثلاثين يوماً من إحداث الجرعة الثانية، مـاعدا تلك

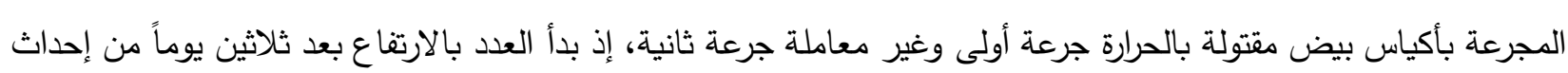
الإصابة الثانية (الجدول 2) يوضـــــح الجدول (3) مقارنة التعداد الكلي لكريات الدم البيض بين مجموعة الفئران المجرعة بأكياس بيض غير معاملة لجرعة واحدة ونظيراتها المجرعة بأكياس بيض غير معاملة بالجرعة الأولى ومقتولة بالحرارة بالجرعة الثانية بعد مدد مختلفة 
(بالايام) من إحداث الإصـابة. بعد 3 أيام من إحداث الإصـابة الثانية، لوحظ ارتفاع في معدلات أعداد كريات الدم البيض. وبعد


الإصابة الثانية، فقد لوحظ انخفاض واضح في معدلات أعداد الكريات. وعند مقارنة أعداد الكريات البيض في الفئران المجرعة لمرة واحدة فقط بأكياس بيض مقتولة مع نظيراتها المجرعة جرعة أولى بأكياس بيض مقتولة لجرعة واحدة وجرعة ثانية لأكياس بيض غير معاملة ، لوحظ بانه بعد 3 أيام من إحداث الإصــــابة


من إحداث الإصابة الثانية فقد لوحظ الارتفاع في أعداد الكريات.

الجدول (1): معدلات التعداد الكلي لكريات الدم البيض في الفئران البيض المجرعة بأكياس بيض غير معاملة ومقتولة بالحرارة بعد مدد مختلفة (بالايام) من إحداث الإصابة

\begin{tabular}{|c|c|c|c|}
\hline \multicolumn{3}{|c|}{ المعدل } & \multirow{2}{*}{ المدة بالأيام / المجاميع } \\
\hline 30 & 15 & 3 & \\
\hline $2566.67 \mathrm{~b}$ & $3425.00 \mathrm{a}$ & $2075.00 \mathrm{bc}$ & سيطرة سالبة \\
\hline 6308.33 a & 3658.33 a & $3150.00 \mathrm{ab}$ & مجرعة غير معاملة مرة واحدة \\
\hline $2444.40 \mathrm{~b}$ & $2394.43 \mathrm{~b}$ & $1300.00 \mathrm{c}$ & مجرعة مقتولة لمرة واحدة \\
\hline
\end{tabular}

المعدلات ذات الحروف المختلفة عمودياً أو افقيا تعني وجود فرق معنوي عند مستوى 0.05>0 باستخدام اختبار دنكن

الجدول (2): معدلات التعداد الكلي لكريات الام البيض في الفئران البيض المجرعة بأكياس بيض غير معاملة جرعة أولى وغير معاملة أو مقتولة في الحرارة في الجرعة الثانية بعد مدد مختلفة (بالايام) من إحداث الإصابة

\begin{tabular}{|c|c|c|c|}
\hline \multicolumn{3}{|c|}{ المعدل } & \multirow{2}{*}{ المدة بالأيام } \\
\hline 30 & 15 & 3 & \\
\hline $3416.67 \mathrm{~b}$ & $9987.50 \mathrm{a}$ & $2975.00 a b$ & مجرعة غير معاملة مرتين \\
\hline $3333.30 \mathrm{~b}$ & $4775.00 \mathrm{~b}$ & $3700.00 \mathrm{a}$ & مجرعة غير معاملة أولاً ومقتولة ثانياً \\
\hline $4466.67 \mathrm{ab}$ & $1813.87 \mathrm{c}$ & $2287.50 \mathrm{ab}$ & مجرعة مقتولة أولاً و غير معاملة ثانياً \\
\hline
\end{tabular}

المعدلات ذات الحروف المختلفة عمودياً أو افقياً تعني وجود فرق معنوي عند مستوى (P (P) باستخدام اختبار دنكن 
الجدول (3): مقارنة بين معدلات التعداد الكلي لكريات الدم البيض في الفئران البيض المجرعة بأكياس بيض غير معاملة لجرعة واحدة ونظيراتها المجرعة بأكياس بيض غير معاملة في الجرعة الأولى وغير معاملة و مقتولة بالحرارة في الجرعة الثانية باستخدام اختبار t بعد مدد مختلفة (بالايام) من إحداث الإصابة

\begin{tabular}{|c|c|c|c|}
\hline المعدل المعل & المجاميع المجرعة & المعدل (مرة غير معاملة واحدة) & المدة (يوم) \\
\hline 2975.00 & غير معاملة مرتين & \multirow{2}{*}{3150.00} & \multirow{2}{*}{3} \\
\hline 3700.00 & غير معاملة أولاً ومقتولة ثانياً & & \\
\hline *** 9987.50 & غير معاملة مرتين & \multirow{2}{*}{3658.33} & \multirow{2}{*}{15} \\
\hline 4775.00 & غير معاملة أولاً ومقتولة ثانياً & & \\
\hline 3416.67 & غير معاملة مرتين & \multirow{2}{*}{6308.33} & \multirow{2}{*}{30} \\
\hline 3333.30 & غير معاملة أولاً ومقتولة ثانياً & & \\
\hline
\end{tabular}

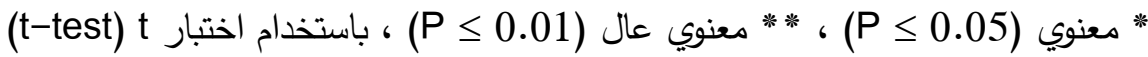

الجدول (4): مقارنة بين معدلات التعداد الكلي لكريات الدم البيض في الفئران البيض المجرعة بأكياس بيضمقتولة لجرعة واحدة ونظيراتها المجرعة بأكياس بيض مقتولة في الجرعة الأولى وغير معاملة في الجرعة الثانية باستخدام اختبار t بعد مدد مختلفة (بالايام) من إحداث الإصابة

\begin{tabular}{|c|c|c|c|c|}
\hline المعدل & المجاميع المجرعة & 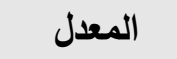 & مرة واحدة معاملات مختلفة & المدة (يوم) \\
\hline 2287.50 & مقتولة أولاً و غير معاملة ثانيا & 1300.00 & مقتولة & 3 \\
\hline 1813.87 & مقتولة أولاً و غير معاملة ثانيا & 2394.43 & مقتولة & 15 \\
\hline 4466.67 & مقتولة أولاً و غير معاملة ثانيا & 2444.40 & مقتولة & 30 \\
\hline
\end{tabular}

Differential Leukocyte Count (DLC)

التعداد التفاضلي لكريات الام البيض تبين من الجداول (8-5) التغيرات الحاصــلة في معدلات التعداد التفاضـلـي لكريات الدم البيض في الفئران المصــابة، تجريبيا، بطفيل البويغيات الخبيئة، أما من خلال تجريعها بأكياس بيض الطفيل غير المعاملة أو المقتولة بالحرارة، جرعة واحدة أو جرعتين. عند تجريع الفئران بأكياس بيض غير معاملة غير معاملة، لجرعة واحدة، لوحظ وجود تتاسب عكسي بين أعداد العدلات واللمفيات خلال فترات الفحص، إذ كانت أعداد اللمفيات مرتفعة مقارنة بأعداد العدلات المنخفضة والتي لم يلحظ فيها فرقا يذكر عن مجموعة السيطرة السالبة. أما عند إحداث الإصـابة بأكياس بيض مقتولة لجرعة واحدة فقد لوحظ حدوث انخفاض في أعداد اللمفيات خلال فترات الفحص صـاحبه ارتفاع واضــــ في أعداد العدلات للفترات نفسـها. أما الحمضــات ووحيدات النواة بقيت بصورة عامة منخفضة خلال فترات الفحص ولكافة مجاميع الفئران المجمعة، جدول (5). 
وعند إحداث الإصـابة بأكياس بيض غير معاملة لجرعتين أو جرعة أولى غير معاملة والثانية مقتولة بالحرارة، لوحظ أن النتائج متقاربة مع نظيراتها المجرعة بأكياس بيض غير معاملة جرعة واحدة فيما يخص اللمفيات والعدلات. أما عند إعطاء جرعة أولى مقتولة وجرعة ثانية غير معاملة فقد لوحظ ارتفاع في معدلات اللمفيات صساحبه انخفاض في أعداد العدلات مقارنة

بنظيراتها المجرعة بأكياس بيض مقتولة بالحرارة لجرعة واحدة، وبالنسبة للحمضات ووحيدات النواة فلم يلحظ فيها تغير يذكر . يلاحظ من جدول (7) وجود انخفاض معنوي (P معاملة لجرعتين مقارنة بنظيراتها المجرعة بأكياس بيض غير معاملة لجرعة واحدة بعد ثلاثة ايام من إحداث الإصابة الثانية.

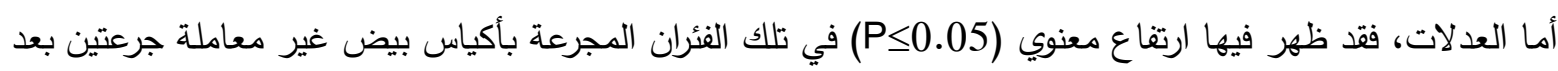
ثلاثة وخمســة عشـر يوماً من إحداث الإصـــابة الثانية، وكذلك كان الارتفاع معنوياً (P (0.001 بعد ثلاثين يوماً من إحداث الإصــابة الثانية عندما كانت الجرعة الثانية مقتولة، ولم يلحظ أي تغيير معنوي في أعداد الحمضــات. أما وحيدات النواة فلم يلحظ فيها أي تغير معنوي بعد ثلاثة أيام من إحداث الإصـابة الثانية، في حين لوحظ حدوث انخفاض معنوي في مجموعة الفئران المجرعة جرعة ثانية بأكياس بيض مقتولة (P (P) بعد خمسـة عثر يوماً و ثلاثين يوماً من إحداث الإصابة الثانية.

يوضــــح جدول (8) أن عدد الخلايا اللمفية ازداد معنوياً (P كجرعة أولى وغير معاملة بوصـفها جرعة ثانية منذ اليوم الثالث بعد إحداث الإصـابة الثانية، واسـتمر هذا الارتفاع بعد ثلاثين

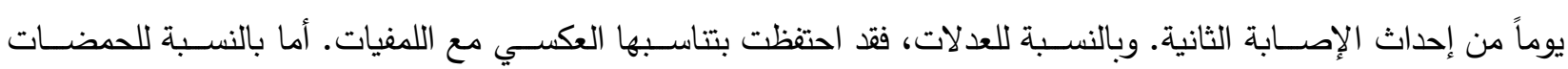
ووحيدات النواة، فلم تكن هناك زيادة معنوية ماعدا بعض الحالات القليلة.

الجدول (5): معدلات التعداد التفاضلي لكريات الدم البيض في الفئران البيض المجرعة باكياس بيض غير معاملة ومقتولة بالحرارة بعد مدد مختلفة (بالايام) من احداث الإصابة

\begin{tabular}{|c|c|c|c|c|c|c|c|c|c|c|c|c|}
\hline \multicolumn{3}{|c|}{ وحيدات النواة } & \multicolumn{3}{|c|}{ الحمضات } & \multicolumn{3}{|c|}{ العلات } & \multicolumn{3}{|c|}{ اللمفيات } & \multirow{2}{*}{ المجاميع } \\
\hline 30 & 15 & 3 & 30 & 15 & 3 & 30 & 15 & 3 & 30 & 15 & 3 & \\
\hline $1.39 \mathrm{~b}$ & $3.33 \mathrm{ab}$ & $0.76 \mathrm{~b}$ & $1.17 \mathrm{a}$ & $3.00 \mathrm{a}$ & $1.33 \mathrm{~b}$ & $7.29 \mathrm{c}$ & $11.00 \mathrm{~b}$ & $8.66 \mathrm{~d}$ & $90.14 a$ & $82.67 \mathrm{a}$ & $89.25 \mathrm{a}$ & سبطرة مالبة \\
\hline $4.11 \mathrm{a}$ & $5.36 \mathrm{a}$ & $0.00 \mathrm{~b}$ & $1.45 \mathrm{a}$ & $2.39 \mathrm{ab}$ & $0.67 \mathrm{~b}$ & $6.85 \mathrm{c}$ & $11.57 \mathrm{~b}$ & $11.03 \mathrm{~cd}$ & $88.61 \mathrm{a}$ & $80.64 a$ & $88.30 \mathrm{a}$ & مجرعة غير معاملة مرة واحدة \\
\hline $0.00 \mathrm{~b}$ & $1.01 \mathrm{bc}$ & $2.56 \mathrm{~b}$ & $1.87 \mathrm{a}$ & $0.00 \mathrm{~b}$ & $1.11 \mathrm{~b}$ & $13.81 \mathrm{a}$ & $33.78 \mathrm{a}$ & $61.54 \mathrm{a}$ & $84.30 \mathrm{~b}$ & $65.20 \mathrm{~b}$ & $34.77 \mathrm{~b}$ & مجرعة مهَّولة هرة واحدة \\
\hline
\end{tabular}

المعدلات ذات الحروف المختلفة عموديا او افقيا تعني وجود فرق معنوي عند مستوى 0.05 > باستخدام اختبار دنكن 
الجدول (6): معدلات التعداد التفاضلي لكريات الدم البيض في الفئران البيض المجرعة باكياس بيض غير معاملة جرعة اولى وغير معاملة ومقتولة بالحرارة في الجرعة الثانية بعد مدد مختلفة (بالايام) من احداث الإصابة

\begin{tabular}{|c|c|c|c|c|c|c|c|c|c|c|c|c|}
\hline \multicolumn{3}{|c|}{ وحيدات النواة } & \multicolumn{3}{|c|}{ الحمضات } & \multicolumn{3}{|c|}{ العدلات } & \multicolumn{3}{|c|}{ اللمفيات } & المجاميع \\
\hline $2.72 b c$ & $1.75 \mathrm{abc}$ & $0.81 \mathrm{c}$ & $1.37 \mathrm{ab}$ & $2.33 \mathrm{a}$ & $0.00 \mathrm{~b}$ & $6.14 \mathrm{~cd}$ & $21.64 \mathrm{a}$ & $29.08 \mathrm{a}$ & $89.77 b$ & $74.27 \mathrm{c}$ & $70.10 \mathrm{a}$ & مجرعة غير معاملة مرتين \\
\hline $0.00 \mathrm{c}$ & $0.00 \mathrm{c}$ & $1.00 \mathrm{c}$ & $0.00 \mathrm{~b}$ & $0.00 \mathrm{~b}$ & $0.00 \mathrm{~b}$ & $15.02 \mathrm{~b}$ & $18.93 \mathrm{ab}$ & $18.97 \mathrm{abc}$ & $84.97 \mathrm{bc}$ & $81.07 \mathrm{bc}$ & $80.02 \mathrm{a}$ & مجرعة غير معاملة اولا ومقتولة ثُانيا \\
\hline
\end{tabular}

المعدلات ذات الحروف المختلفة عموديا او افقيا تعني وجود فرق معنوي عند مستوى 0.05 > باستخدام اختبار دنكن

الجدول (7): مقارنة بين معدلات التعداد التفاضلي لكريات الدم البيض في الفئران البيض المجرعة باكياس بيض غير معاملة بجرعة واحدة ونظيراتها المجرعة باكياس بيض غير معاملة في الجرعة الاولى وغير معاملة ومقتولة بالحرارة في الجرعة الثانية باستخدام اختبار t بعد مدد مختلفة (بالايام) من احداث الاصابة

\begin{tabular}{|c|c|c|c|c|c|c|c|c|c|}
\hline \multicolumn{2}{|c|}{ وحيدات النواة } & \multicolumn{2}{|c|}{ الحمضات } & \multicolumn{2}{|c|}{ العدلات } & \multicolumn{2}{|c|}{ اللمفيات } & \multirow{2}{*}{ المجاميع المجرعة } & \multirow{2}{*}{ المدة (يوم) } \\
\hline | جرعة مزدوجة & جرعة مفردة & جرعة مزدوجة & جرعة مفردة & | جرعة مزدوجة & جرعة مفردة & جرعة مزدوجة & جرعة مفردة & & \\
\hline 0.81 & \multirow{2}{*}{0.0} & 0.0 & \multirow{2}{*}{0.67} & $* 29.08$ & \multirow{2}{*}{11.03} & $* 70.1$ & \multirow[t]{2}{*}{88.30} & غير معاملة مرثين & \multirow{2}{*}{3} \\
\hline 1.0 & & 0.0 & & 18.97 & & 80.02 & & غبر معاملة أولاً ومقتولة ثانياً & \\
\hline 1.75 & \multirow{2}{*}{5.36} & 2.33 & \multirow{2}{*}{2.39} & $* 21.64$ & \multirow{2}{*}{11.57} & 74.27 & \multirow{2}{*}{80.64} & غير معاملة مرتين & \multirow{2}{*}{15} \\
\hline$* 0.0$ & & 0 & & 18.93 & & 81.07 & & غير معاملة أولاً ومقتولة ثانياً & \\
\hline 2.72 & \multirow{2}{*}{4.11} & 1.37 & \multirow{2}{*}{1.45} & 6.14 & \multirow{2}{*}{6.85} & 89.77 & \multirow{2}{*}{88.61} & غير معاملة مرتين & \multirow{2}{*}{30} \\
\hline$* 0.0$ & & 0 & & $* 15.02$ & & 84.97 & & غير معاملة أولاً ومقتولة ثانياً & \\
\hline
\end{tabular}

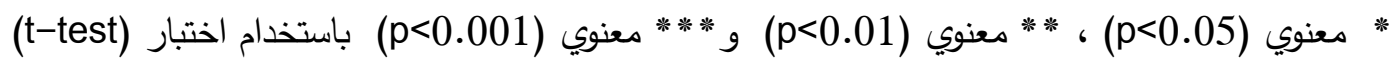

الجدول (8): مقارنة بين معدلات التعداد التفاضــلـي لكريات الدم البيض في الفئران البيض المجرعة باكياس بيض مقتولة بالحرارة لجرعة واحدة ونظيراتها المجرعة باكياس بيض مقتولة بالحرارة في الجرعة الاولى وغير معاملة في الجرعة الثانية باستخدام اختبار t بعد مدد مختلفة (بالايام) من احداث الاصابة

\begin{tabular}{|c|c|c|c|c|c|c|c|c|c|}
\hline \multicolumn{2}{|c|}{ وحيدات النواة } & \multicolumn{2}{|c|}{ الحضات } & \multicolumn{2}{|c|}{ العدلات } & \multicolumn{2}{|c|}{ اللمفيات } & \multirow{2}{*}{ المجاميع المجرعة } & \multirow{2}{*}{ مدة (يوم) } \\
\hline + غير معاملة & جرعة 1 مقتولة & + غير معاملة & جرعة 1 مقتولة & + غير معاملة & |جرعة مقتولة & + غير معاملة & جرعة 1 مقتولة & & \\
\hline 0.43 & 2.56 & 0.00 & 1.11 & ****18.16 & 61.54 & $* * * 81.41$ & 34.77 & مقتولة أولاً وغير معاملة ثانياً & 3 \\
\hline 0.76 & 1.01 & 0.00 & 0.00 & 14.85 & 33.78 & 84.38 & 65.20 & مقتولة أولاً وغير معاملة ثانياً & 15 \\
\hline 0.67 & 0.00 & 1.33 & 1.87 & $* 10.00$ & 13.81 & $* 88.00$ & 84.30 & مقتولة أولاً وغير معاملة ثانياً & 30 \\
\hline
\end{tabular}

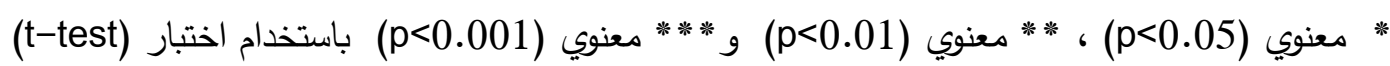

المناقثة

في الدراسة الحالية ظهر اول طرح لأكياس البيض في اليوم الرابع بعد إحداث الإصابة، وذلك عند إحداثها بأكياس بيض غير معاملة. هذه النتيجة تتقق مع ما وجده كل من 21,20,19] Al-Jarjary, Al-Mahmoud Bakir في محافظة نينوى. 
إن هذا التوافق يثـير إلى ان الفترة قبل البائنة (الفترة بين حدوث الإصـابة واول ظهور لأكياس البيض) ثابتة، في الإصـابة غير

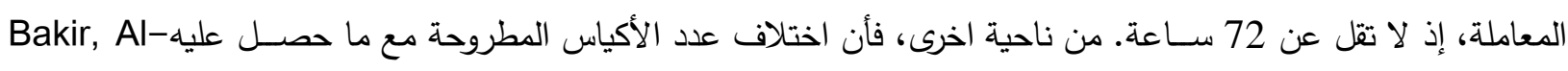
[20,19] Mahmoud أكياس بيض مصدرها العجول، في حين استخدمت Al-Jarjary [21] أكياس بيض مصسرها الإنسـان، كما هو الحال في الدراسـة الحالية. فضـلاً عن ذلك فان الاختلاف في طريقة حساب عدد أكياس البيض المطروحة قد يكون سبب اختلاف النتائج أيضـاً، حيث أن كلا من Bakir, Al-Mahmoud [20,19] اعتمدا حسـاب عدد الأكياس في الغرام الواحد من البراز، في حين استخدمت Al-Jarjary [21] كما هو الحال في الدراسة الحالية، طريقة الحساب لكل حقل مجهري. في الدراسـة الحالية، اسـتمر طرح أكياس البيض في الفئران البيض، في الإصـابة التجريبية بأكياس بيض غير معاملة، منذ اليوم الرابع بعد إحداث الإصابة ولغاية اليوم الخامس والثلاثين بعد إحداثها، ثم توقف طرح الأكياس. عند تعريض أكياس البيض إلى درجة حرارة 70C لمدة 30 دقيقة، لوحظ بان جميع أكياس البيض قد فقدت خمجيتها، Harp et al., Fayer et al., Blewett إذ لم تظهر أكياس البيض في البراز، وهذا يتفق مع ما جاء به الباحثون السـابقون [25,24,23,22] et al., Anderson

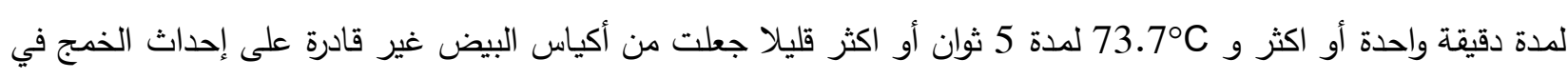
الفئران البيض. وكذلك فانه عند تعريض أكياس البيض لدرجة حرارة 71.7² أو اكثر لمدة دقيقة واحدة جعل من أكياس بيض C. parvum غير قادرة على إحداث الخمج في الفئران البيض التي كانت

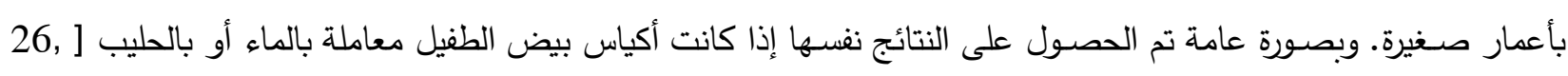
22] ـ من ناحية اخرى فقد اشـار . Fujino et al. [27 إلى أن تعريض أكياس بيض الطفيل C. parvum إلى درجة حرارة C C 70 لمدة 60 ثانية قد أفقد جميع أكياس البيض خمجيتها في الفئران البيض والدجاج أيضـاً. ولتبيان مدى تاثير درجة حرارة

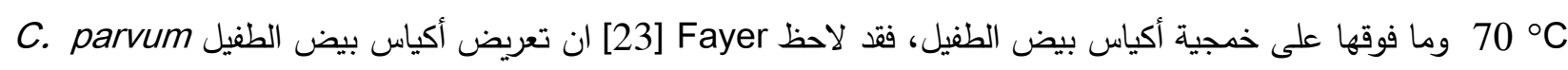
إلى درجة حرارة Co 72.4 أو أعلى لمدة دقيقة واحدة قلل من عدد أكياس البيض الخمجة المطروحة مع البراز من 150000 إلى عدد تراوح بين 0-25 كيس بيض خمج، كذلك فأنه عند تعريض أكياس البيض للدرجة الحرارية نفسها المذكورة سابقا وللفترة


parvum

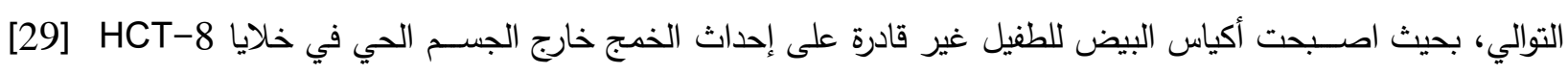
ومن الجدير بالذكر أن .30wman et al [30] اشـاروا إلى ان أكياس البيض يمكن ان تبقى حية في التربة ما لم تتعرض إلى

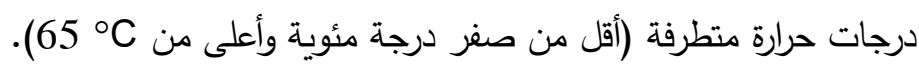
عند استخدام أكياس بيض مقتولة فقد انخفض العدد الكلي لكريات الدم البيض في بداية الإصابة ثم بدأ يرتفع بعد ثلاثين

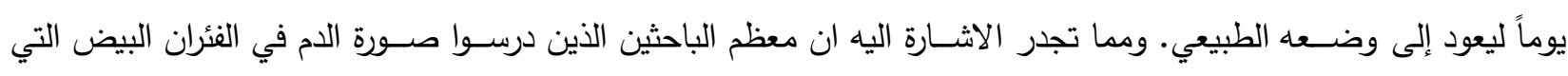

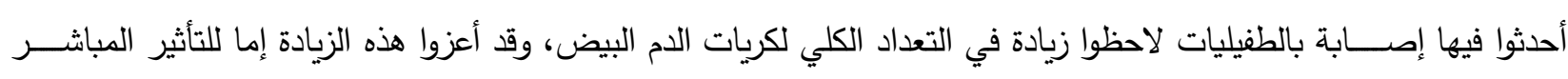

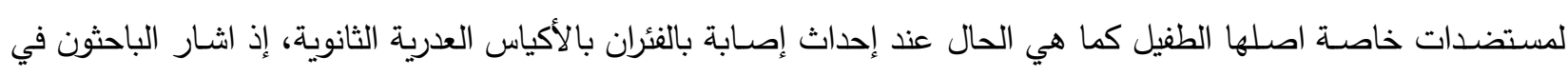


سنوات سـابقة Siracusano,1988, Shepherd, 1991, Profumo ,1994, Jenkins et al., 1986 الى أن سبب

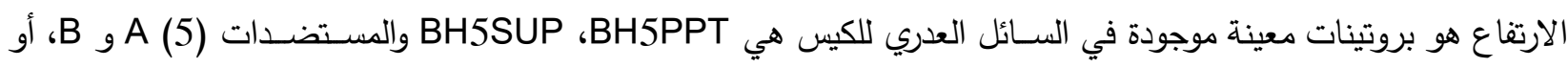

التاثير المباشر للرؤيسات الأولية في الكيس العدري كونها مشطرة غير تخصصية لخلايا T و (B) ـ [34,33,32,31 إن ما لوحظ في الدراسة الحالية من ارتفاع مستمر في التعداد الكلي لكريات الدم البيض عند استخدام أكياس بيض غير معاملة يمكن ان يعزى إلى تتبيط عمل العدلات من قبل مسـضـــات الطفيل، وعليه لم تحفز هذه الخلايا على الهجرة إلى موقع الخمج. وما يدعم هذا الافتراض هو الانخفاض الذي لوحظ عند اســـتخدام أكياس بيض مقتولة بالحرارة الذي ربما ألغى عملية التثبيط هذه وأدى إلى هجرة العدلات الذي أدى بدوره إلى انخفاض التعداد الكلي لكريات الدم البيض.

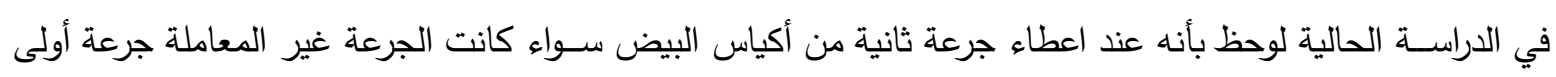
أو ثانية ارتفع العدد الكلي لكريات الدم البيض مقارنة بنظائرها عند اعطاء جرعة واحدة. هذا يثــير إلى ان الجرعة الثانية تزيد من الاسـتجابة المناعية للمضـيف، وقد أكدت ذلك كل من Aghwan, Al- Barrwari [36,35] عند اعطائهما جرعة ثانية Al- Barrwari من المقوسـات الكوندية للفئران البيض بهاف دراسـة الاسـتجابة المناعية الخلطية في المضـيف، إذ أشـارت [36 ان معايير الضد lgM ارتفعت واستمر بقاؤها مرتفعا لفترة 15 يوماً بعد الحقن الثاني.

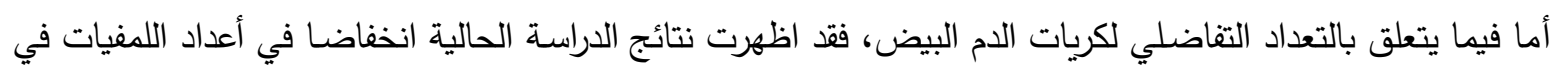
الأيام الثلاثة الأولى بعد إحداث الإصـابة صـاحبه ارتفاع في أعداد العدلات وانخفاض في أعداد الحمضــات وارتفاع في أعداد


الطفيف الذي لوحظ في أعداد اللمفيات خاصــــة في الايام الثلاثة الأولى من قبل Janssen et al [37 عند معاملتهم للفئران بأحد الأجزاء السامة المستخلصة من سائل الأكياس العدرية وهو F7. كذلك لوحظ هذا الانخفاض من قبل باحثين اخرين

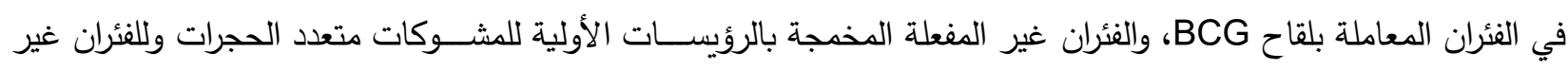

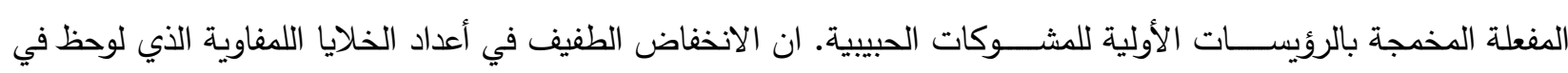
الدراسـة الحالية قد يكون بسبب ارتفاع أعداد العدلات التي ولم تهاجر إلى مواقع الخمج وقد يكون الانخفاض للموازنة مع ارتفاع العدلات. [41,40,39,38

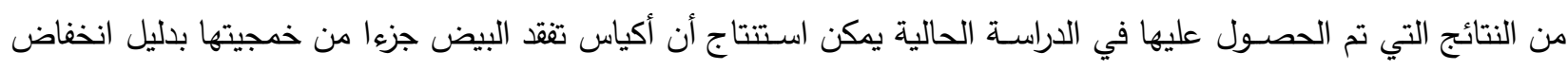
فترة بقائها في المضيف وعدد أكياس البيض المطروحة، في حين تكون أكياس البيض حساسـة عند درجة الحرارة (Co C انها تقتل بســـرعة في هذه الدرجة الحرارية. قد تحفز الإصــــابة بأكياس البيض غير المعاملة الاســـــابة المناعية الطبيعية (اللانوعية) من خلال تحفيز الخلايا المناعية على التكاثر.

المصادر

1. Hendrix CM Diagnostic Veterinary Parasitology. $2^{\text {nd }}$ ed., Mosby, pp. 19-34 (1998) .

2. Das P, Roy SS, Mitradhar K, Dutta P, Bhattacharya MK, Sen A, Ganguly S, Bhattacharya SK, Lal AA, Xiao L, India. J. Clin. Microbiol., 44(11): 4246-4249 (2006) . 
3. Fayer $\mathrm{R}$ Advances in Cryptosporidium research. International Giardia and Cryptosporidium conference. Moreilia-Michoacan, Mexico (Spiral Bound Book) (2007).

4. Luna LG) Manual of Histological Staining Methods of the Armed Forces Institute of Pathology. $3^{\text {rd }}$ ed. The Blakiston Division, McGraw-Hill Book Comp., New York (1968) .

5. OIE World Organization for Animal Health Manual of Diagnostic Tests and Vaccines for Terrestrial Animals. $5^{\text {th }}$ ed, Retrieved from Internet: http://www.oie.int / (2005).

6. Henriksen SA, Pohlenz JF (1981) Acta Vet. Scand., 22: 594-596.Al-Barrwari, N.J.S., M. Sc. Thesis, Coll. Edu.. University of Mosul (2006) . (In Arabic).

7. Ma P, Soave R. J. Infect. Dis., 147: 824-828 (1983).

8. Deluol WH Color Atlas of Parasitology. Vol. 2 Format Utile, France: pp. 34-63 (1999).

9. Feire-Santos F, Oteiza-Lopes AM, Vergara-Castiblanco CA, Area-Mazas ME, Vet. Parasitol., 87: 1-7 (1999).

10. Anderson BC, J. Am. Vet.Med. Assoc., 178: 982-984 (1981).

11. Lindsay DS, Woods KM, Upton SJ, Blagburn BL. Vet. Parasitol., 89: 307-311(2000).

12. Woods KM, Nesterenko MN, Upton SJ. Ann. Trop. Med. Parasitol., 90(6): 603-615 (1996).

13. Viu M, Quilez J, Sanchez-Acedo C, Delcacho E, Lopez-Bernad F. Vet. Parasitol., 90: 163170 (2000).

14. Khalifa AM, Ibrahim IR, El-Kerdany ED. East Medit. Hlth. J., 6(5): 908-918 (2000).

15. Waynforth HB Experimental and Surgical Technique in the Rats. Academic Press Inc., London, LTDNWI, p. 29 (1980).

16. Talib VH, Director C A Handbook of Medical Laboratory Technology. Tara Printers. Noida., 9-14 (1988).

17. Dacie JV, Lewis SM Parasitical Haematology. $6^{\text {th }}$ ed., Churchill Livingstone Publication (1986).

18. Al-Rawi K.M., KHalaf-Allah A.M. Design and Analysis of Agricultural Experiments. Text book print Mosul University, Iraq (1980). (In Arabic).

19. Bakir, M. H., Ph.D. Thesis, coll. Vet. Med. University of Mosul, Iraq (2005). (In Arabic).

20. Al-Mahmoud, S.S. F., M. Sc. Thesis, coll. Vet. Med. University of Mosul, Iraq (2006). (In Arabic)

21. Al-Jarjary, S.A.A., Ph. D. Thesis, Coll. Sci. University of Mosul, Iraq (2006). (In Arabic).

22. Harp JA, Fayer R, Pesch BA, Jackson GJ., Appl. Environ. Microbiol., 62(8): 2866-2868 (1996).

23. Fayer R., Appl. Environ. Microbiol., 60(8): 2732-2735 (1994).

24. Blewett DA Quantitative techniques in Cryptosporidium research. pp. 85-98. In: KW Angus and DA Blewett (eds.), Proc., $1^{\text {st }}$ Int. Workshop. Cryptosporidiosis, Edinburgh, Scotland (1989).

25. Anderson BC (1985)., Am. J. Public Hlth., 75: 1433-1434.

26. Casemore DP, Watkins J (1999), . DETR: 56FP.

27. Fujino T, Matsui T, Kobayashi F, Haruki K, Yoshino Y, Kajima J, Tsuji M., J. Vet. Med. Sci., 64(3): 199-200 (2002).

28. Donnelly JK, Stentiford EI., Manag. Hlth., 8(4): 112-123 (1997).

29. Moriarty EM, Duffy G, McEvoy JM, Caccio S, Sheridan JJ, McDowell D, Blair IS., J. Appl. Microbiol., 98(3): 618-623 (2005). 
30. Bowman DD, Lynn RC, Eberhard ML Georgis Parasitology for Veterinarians. $8^{\text {th }}$ ed., Saunders, pp. 98-100 (2003).

31. Siracusano A, Teggi A, Quintieri F, Notargiacomo S, De Rosa F, Vicari G ., Clin. Exp. Immunol., 72: 400-405 (1988).

32. Shepherd JC, Antiken A, McManus DP., Mol. Biochem., Parasitol., 44: 81-90 (1991).

33. Profumo E, Ortona E, Rigano R, Gioia I, Notargiacomo S, Ioppolo S., Parasit. Immunol., 16(8): 393-398 (1994).

34. Jenkins DJ, Dixon JB, Ross G, Cox DA., Ann. J. Trop. Med. Parasitol., 80: 43-47 (1986).

35. Aghwan, S.S., ph. d. thesis, coll. vet. med. university of mosul, Iraq (2005). (in Arabic).

36. Al-Barrwari, N.J.S., M. Sc. Thesis, Coll. Edu.. University of Mosul (2006). (In Arabic).

37. Janssen D, Rueda MC, DeRycke PH, Osuna A., Parasit. Immunol., 19: 149-160 (1997).

38. Reuben JM, Tanner CE, Portelance V., Infect. Immunol., 21: 135-139 (1979).

39. Ali-Khan Z., J. Parasitol., 60(2): 236-242 (1974).

40. Du T, Ali-Khan Z., J. Exp. Pathol., 71: 313-335 (1990).

41. Al-Mutaywiti, S.S.Y., M. Sc. Thesis. Coll. Edu. University of Mosul (2005). (In Arabic). 